Published in final edited form as:

J Pediatr. 2014 May ; 164(5): 1091-1098.e3. doi:10.1016/j.jpeds.2013.12.029.

\title{
Effect of relative weight group change on NMR spectroscopy derived lipid particle size and concentrations among adolescents
}

\author{
Russell Jago, $\mathrm{PhD}^{1}$, Kimberley L. Drews, $\mathrm{PhD}^{2}$, James D. Otvos, $\mathrm{PhD}^{3}$, Gary D. Foster, \\ $\mathrm{PhD}^{4}$, Marsh D. Marcus, $\mathrm{PhD}^{5}$, John B. Buse, MD, $\mathrm{PhD}^{6}$, Michele Mietus-Snyder, MD, $\mathrm{PhD}^{7}$, \\ and Steven M. Willi, MD ${ }^{8}$ on behalf of the HEALTHY Study Group ${ }^{*}$ \\ ${ }^{1}$ Centre for Exercise, Nutrition \& Health, School for Policy Studies, University of Bristol \\ ${ }^{2}$ The George Washington University Biostatistics Center \\ ${ }^{3}$ LipoScience, Inc \\ ${ }^{4}$ Center for Obesity Research and Education, Temple University \\ ${ }^{5}$ University of Pittsburgh School of Medicine \\ ${ }^{6}$ University of North Carolina School of Medicine \\ ${ }^{7}$ George Washington University School of Medicine \& Health Sciences \& Children's National \\ Medical Center \\ ${ }^{8}$ Children's Hospital of Philadelphia \& Perelman School of Medicine of the University of \\ Pennsylvania
}

\section{Abstract}

Objective-To examine whether longitudinal changes in relative weight category (as indicated by change in BMI classification group) were associated with changes in nuclear magnetic resonance (NMR) derived lipoprotein particles among US youth.

\begin{abstract}
Study design-Secondary analysis of data from clustered RCT. BMI and fasting blood samples were obtained from 2069 participants at the start of $6^{\text {th }}$ grade and end of $8^{\text {th }}$ grade. BMI was categorized as normal weight, overweight or obese at both time points. Lipoprotein particle profiles were measured using NMR spectroscopy at both time points. Regression models were used to examine changes in relative weight group and change in lipoprotein variables.
\end{abstract}

(C) 2013 Mosby, Inc. All rights reserved.

Address for correspondence: Russell Jago, PhD, Centre for Exercise, Nutrition and Health, School for Policy Studies, University of Bristol, 8 Priory RD, Bristol BS8 1TZ, UK. russ.jago@bris.ac.uk, Tel: 44 (0) 1179546603 Fax: 44(0) 1173310418.

List of HEALTHY Study Group members is available at www.jpeds.com (Appendix).

The other authors declare no conflicts of interest.

Registered with ClinicalTrials.gov: NCT00458029

Publisher's Disclaimer: This is a PDF file of an unedited manuscript that has been accepted for publication. As a service to our customers we are providing this early version of the manuscript. The manuscript will undergo copyediting, typesetting, and review of the resulting proof before it is published in its final citable form. Please note that during the production process errors may be discovered which could affect the content, and all legal disclaimers that apply to the journal pertain. 
Results-38\% of participants changed relative weight category (BMI group) over the 2.5 year study period. Low density lipoprotein cholesterol and non-high density lipoprotein cholesterol decreased almost universally, but more with improved BMI category. There were adverse effects on LDL size and total LDL particles, high density lipoprotein size and cholesterol for participants who remained obese or whose relative weight group worsened. Changes in relative category had no impact on HDL particles.

Conclusion-Improvement in relative weight group from $6^{\text {th }}$ to $8^{\text {th }}$ grade was associated with favorable changes in non-HDL-C, VLDL size, LDL size, HDL size and LDL particles, but had no effect on HDL particles. Findings indicate that an improvement in relative weight group between $6^{\text {th }}$ and $8^{\text {th }}$ grade had an effect on NMR derived particles sizes and concentrations among a large group of adolescents, which overrepresented low-income minorities.

\section{Keywords}

Lipoproteins; Obesity; Pediatrics; Prevention; Risk Factors; BMI

There is substantial evidence that insulin resistance in adults and children (1) is associated with high triglyceride levels and low levels of high density lipoproteins. Recent adult studies using nuclear magnetic resonance (NMR) spectroscopy have suggested that low density lipoprotein particle (LDL-P) concentration and size may have stronger associations with insulin resistance and the metabolic syndrome than traditional lipoprotein lipid measures (2). LDL-P and LDL particle size may provide early markers for cardio-metabolic risk and both incident type 2 diabetes (T2DM) and cardiovascular disease (CVD) $(3,4)$.

Emerging evidence indicates that NMR lipoprotein profiles are associated with obesity and insulin resistance in children. For example, Magge et al reported there was no difference in levels of low-density lipoprotein cholesterol (LDL-C), high density lipoprotein cholesterol (HDL-C) and triglycerides (TG) comparing obese, children with pre-diabetes with obese but children with normo-glycemia (5). However, participants with pre-diabetes had higher concentrations of small LDL-P and a smaller average LDL particle size. Moreover, a number of studies have shown that obese children have higher levels of small and total LDL-P than non-obese children(6, 7).

In adults, a diet and exercise regime that reduces total and visceral fat and improves insulin sensitivity has been shown to yield favorable changes in NMR-derived lipoprotein particles (8). Longitudinal data have shown that non-obese adults who were overweight in childhood have levels of elevated lipids comparable with individuals who had a healthy weight at both time points (9). Thus, we examined the associations between 2.5-year changes in relative weight category and changes in NMR-derived lipoprotein particles in $2069,6^{\text {th }}$ graders, $75 \%$ of whom were Black or Latino, and 50\% of whom were overweight or obese.

\section{METHODS}

This report is an analysis of stored blood from the HEALTHY Study, a US National Institute of Diabetes and Digestive and Kidney Diseases (NIDDK) cluster randomized controlled trial that aimed to reduce the prevalence of risk factors for type 2 diabetes 
mellitus among middle school children $\left(6^{\text {th }}-8^{\text {th }}\right.$ grade $)$. The main study design has been detailed elsewhere $(10,11,12)$. Briefly, participants were recruited from 42 middle schools across the US. Schools had at least $50 \%$ of students eligible for free or reduced-price lunch or belonging to an ethnic minority group and an annual student attrition rate $\leq 25 \%$. The intervention included changes to the physical education curriculum school food service, health education, and a school wide social marketing campaign (11,13-17). The sample for this study is limited to participants who provided parental consent and child assent for ancillary analyses of stored blood, and for whom complete data were available. The study was approved by the Institutional Review Boards at each field center, and written informed parental consent and child assent were obtained.

Height and body mass were measured without shoes using the Prospective Enterprises PEAIM-101 stadiometer and the SECA Corporation Alpha 882 electronic scale. Body Mass Index $\left(\mathrm{kg} / \mathrm{m}^{2}\right)$ was calculated and converted to an age- and sex-specific BMI percentile using CDC 2000 criteria (18). Students with BMI $\geq 5^{\text {th }}$ percentile and $<85^{\text {th }}$ percentile were classified as healthy weight. The healthy weight range was then subdivided into 2 groups: BMI $\geq 5^{\text {th }}$ percentile and $<50^{\text {th }}$ percentile and BMI $\geq 50^{\text {th }}$ percentile and $<85^{\text {th }}$ percentile. Youth with BMI $\geq 85^{\text {th }}$ percentile but $<95^{\text {th }}$ percentile were classified as overweight, those with BMI between $100 \%$ and $119 \%$ of the $>95^{\text {th }}$ percentile classified as obese and those at or above $120 \%$ of the $95^{\text {th }}$ percentile classified as severely obese (19) and those with BMI $<5^{\text {th }}$ percentile were classified as underweight. Waist circumference was taken using a Gulick tape measure (G-tape) with a tension device on bare skin measured just above the iliac crest.

At baseline (beginning of $6^{\text {th }}$ grade) and follow-up (end of $8^{\text {th }}$ grade) fasting blood samples were collected from all participants. Standard lipid profiles including total cholesterol (TC), TG, and HDL-C were measured by CDC-standardized direct assay at the University of Washington (20). LDL-C was calculated using the Friedewald equation (21). Analyses of glucose were performed using reagent from Roche Diagnostics. Insulin was measured by a two-site immuno-enzymometric assay. Fasting insulin (performed using a Tosoh 1800 autoanalyzer) and glucose (performed on a Roche P module auto-analyzer by the hexokinase method) were used to calculate the homeostatic model assessment of insulin resistance (HOMA-IR) according to the formula: Glucose*Insulin / [ $\mu \mathrm{U} / \mathrm{L}] 22.5$ (22).

Lipoprotein particle profiles were measured by NMR spectroscopy with the LipoProfile-3 algorithm at LipoScience, Inc (Raleigh, NC) on frozen EDTA plasma specimens of participants who provided informed consent for ancillary studies. VLDL, LDL and HDL subclasses were quantified from the amplitudes of their spectroscopically-distinct lipid methyl group NMR signals, and weighted-average particle sizes were derived from the sum of the diameter of each subclass multiplied by its relative mass percentage based on the amplitude of its methyl NMR signal. ${ }^{21}$ Diameter range estimates for the subclasses were as follows: large VLDL-P, >60 nm; medium VLDL-P, 35-60 nm; small VLDL-P, 29-35 nm; intermediate-density lipoprotein particles (IDL-P), 23-29 nm; large LDL-P, 20.5-23 nm; small LDL-P, 18 to $20.5 \mathrm{~nm}$ and very small LDL-P <20.5 nm); large HDL-P, 9.4-14 nm; medium HDL-P, 8.2 to $9.4 \mathrm{~nm}$; small HDL-P, 7.3-8.2 nm. VLDL-P, LDL-P and HDL-P are the totals of the particle numbers of the respective VLDL, LDL and HDL subclasses. Also 
reported is a multivariate lipoprotein insulin resistance score (LP-IR) which is derived by combining the 6 lipoprotein subclass and size measures most strongly associated with insulin resistance (large VLDL-P, small LDL-P, large HDL-P, and VLDL, LDL, and HDL size) (23). LP-IR values range from 0 (most insulin sensitive) to 100 (most insulin resistant). Inter-assay reproducibility (coefficient of variation), determined from 80 replicate analyses of 8 plasma pools over 20 days, was $6 \%$ for LP-IR, 8, 3, and $2 \%$ for total VLDL-P, LDL-P, and HDL-P; $0.7 \%$ for LDL and HDL size; $4 \%$ for VLDL size; 7, 13, and 22\% for large, medium, and small VLDL-P; 43, 12, and 10\% for IDL-P, large, and small LDL-P; and 9, 14, and $6 \%$ for large, medium, and small HDL-P, respectively.

Pubertal status was self-reported using the Pubertal Development Scale (24) and converted to pubertal stage groups consistent with the five pubertal stages outlined by Tanner (25). Ethnicity and household education were obtained via parental report and sex was selfreported.

\section{Statistical analyses}

We created 7 categories to examine shifts in relative weight categories from grades 6 through 8 (categories with small numbers were collapsed): (1) overweight to obese or severely obese; (2) healthy weight to overweight, obese, or severely obese; (3) stayed obese or severely obese; (4) stayed overweight; (5) stayed healthy weight; (6) overweight to healthy weight; and (7) obese or severely obese to overweight or healthy weight. Categories were collapsed further for modeling because of small cell sizes; specifically the first $2 \mathrm{BMI}$ categories collapsed into a "worsened" category and the last 2 categories into an "improved" category. Finally, underweight students $(\mathrm{N}=43,2 \%)$ were excluded from modeling as shifting to the healthy weight range was not expected to be associated with increased risk.

Descriptive statistics, including means, standard deviations, and percentages were calculated for all variables. The effect of the intervention upon NMR variables was examined using general linear mixed models which took into account sources of variability within and between schools and controlling for baseline values of the NMR variables. As these analyses indicated no consistent effect of the intervention on NMR variables, we evaluated whether longitudinal shifts in relative weight group differed by sex, race/ethnicity, sixth-grade pubertal stage, and highest household education level by using separate general linear mixed models that adjusted for school intervention status and took into account sources of variability within and between schools and controlled for baseline BMI percentiles. Separate mixed models were also used to analyze associations between shifts in relative weight group and changes in lipoprotein measures. Baseline lipoprotein values of interest, school intervention status, sex, race/ethnicity, sixth-grade pubertal stage and highest household education level were included as covariates. All models tested for shifts in relative weight category as main effects. Covariates were also tested as main effects as well as the interaction between the covariates and BMI category shift when the covariates were significant. There was no pattern of significance with the covariates across all models, but based on the results in previous work, subgroup analysis was performed by sex where the interaction between sex and BMI category shift was statistically significant: small LDL-P, HDL size and LP-IR (10). To evaluate the impact of specific shifts in relative weight 
category, we conducted pair-wise comparisons between each of the shift categories. Pvalues $<0.05$, with Bonferroni corrected p-values applied to multiple comparisons, were considered significant. SAS 9.2 statistical software (SAS Institute, Cary, NC) was used for analyses.

\section{RESULTS}

Participant demographic information is presented for all 2069 participants and by sex in Table I (available at www.jpeds.com). Boys were more likely to be overweight and obese than girls. Demographic information and baseline lipoprotein profiles of the participants included and excluded from the analyses due to incomplete data or being classed as "underweight" are presented in the Figure (available at www.jpeds.com). There was a higher BMI percentile (73.6 vs. $67.6, \mathrm{p}=0.0047)$ and lower HDL-C $(52.5$ vs. $55.0 \mathrm{mg} / \mathrm{dL}, \mathrm{p}=$ 0.0296 ) in those included, vs. those excluded, from NMR analysis.

Table II presents information regarding changes in relative weight categories during the period from $6^{\text {th }}$ to $8^{\text {th }}$ grade. The majority of children (62\%) did not change their BMI category. Consistent with the overall results of the trial (12), more children showed an improvement versus a worsening in their relative weight category (479 vs. $306, \mathrm{p}<0.0001$ ).

The median levels (with inter-quartile ranges) or mean (plus 95\% confidence intervals) of each of the variables are presented for all $6^{\text {th }}$ grade, $8^{\text {th }}$ grade variables as well as the difference $\left(8^{\text {th }}\right.$ grade $-6^{\text {th }}$ grade $)$ are shown in Table III. There was a mean increase in insulin levels and HOMA-IR but a mean decrease in the number of LDL particles across all participants.

The medians and inter-quartile ranges and change from $6^{\text {th }}$ to $8^{\text {th }}$ grade for LDL and HDL measures related to change in relative weight category are presented in Table IV, which also includes a summary of evidence documenting significant changes of these variables among participants as a function of shift in relative weight category. The information in the last column therefore indicates the comparisons that showed a significant relationship between weight category change and variable of interest after adjustment for multiple testing.

Although LDL-C fell in all categories, the greatest decline was present in those whose relative weight group improved. It is noteworthy that LDL-C was around 10-15\% higher in the participants who stayed obese than the participants who remained in the healthy weight group, and the magnitude of the between group disparity in LDL-P was much higher (around 50\%). This difference could be explained by the smaller LDL particle size in the group that remained obese. Total LDL-P increased in the BMI worsened group but decreased in the BMI improved group suggesting a benefit of improving BMI group on CVD risk.

The medians and inter-quartile ranges and change from $6^{\text {th }}$ to $8^{\text {th }}$ grade of HOMA-IR and the lipid and lipoprotein particle measures most strongly associated with insulin resistance are presented in Table V. When the BMI category improved, VLDL size decreased, LDLsize increased and small LDL-P decreased. Conversely, when the BMI category worsened, VLDL size increased and there was a downstream decrease in LDL size and an increase in 
small and total LDL-P. The observed changes in HDL particle size paralleled changes in LDL size; there was an increase in large HDL with a decrease in BMI category and a reduction in large HDL when BMI category increased. There was no evidence of pair-wise differences in HDL-P, however. Also noteworthy among these data were the differences in the HOMA-IR and TG/HDLC levels of the group that remained obese when compared with those remaining at a healthy weight. Similar trends were evident for LP-IR (a composite lipoprotein / insulin score), indicating a difference in potential risk of insulin resistance.

The Figure shows the change in the three variables for which there was a sex interaction (small LDL-P, HDL size and LP-IR), and indicates that for small LDL-P the mean adjusted change was greater in boys than girls in all worsening groups with a particularly marked difference among the BMI increased group. There was a comparable pattern for both HDL size and LP-IR indicating that for these three variables increase in BMI group appears to have a more marked effect on boys than girls.

\section{DISCUSSION}

The present findings expand the current understanding of obesity-related risk factors in youth, by providing new information about the impact of change in relative weight category on NMR variables. In this study, the overall number of HDL particles (HDL-P) did not appear to be related to change in relative weight category, but change in category was associated with change in HDL particle size. This finding is consistent with several recent studies which have reported that lifestyle interventions have yielded changes in particle subclass distribution but not the number of particles $(26,30)$. The full functional significance of HDL subspecies is not known, but an abundance of the larger species may reflect improved insulin sensitivity (31). A relatively greater depletion of large HDL subspecies compared with the smaller forms has been observed in patients with metabolic syndrome (32) and type-2 diabetes (33), suggesting that decreased HDL-P may also be a sensitive risk biomarker for these inflammatory conditions (34). Collectively, these findings suggest that HDL-P is difficult to change with drugs or modest lifestyle intervention, but increased particle size may reflect improved cardiometabolic status.

The analyses reported here demonstrate that with a worsening of relative weight group there are increased numbers of small cholesterol-poor LDL subspecies. Small LDL-P are cleared 30-50\% less efficiently than larger particles, and therefore linger in the vascular space, raising the total LDL-P concentration. Higher levels of LDL-P increase the susceptibility to vascular wall interactions which can lead to atherogenesis.(39) Meanwhile, more triglyceride-rich HDL are also generated and metabolized to smaller, more rapidly-cleared HDL subspecies.(34) It has been reported that premature coronary endothelial dysfunction and atherosclerosis in a cohort of adults referred for evaluation of chest pain correlate with LDL-P and inversely with HDL-P, independent of traditional cholesterol measures.(40) Collectively, these findings demonstrate that NMR-derived lipoprotein measures are markers of cardiometabolic risk that track with BMI changes in children, with implications for CVD risk reduction. 
The present data show changes in NMR lipid measures from $6^{\text {th }}$ to $8^{\text {th }}$ grade were associated with increased cardiovascular risk for subjects who became or remained obese. These longitudinal changes reflected a more atherogenic lipoprotein profile (with increased VLDL size and decreased LDL and HDL size due to a shift toward smaller LDL and HDL particles), with nascent or persistent obesity. In contrast, over the 2.5 year study interval, traditional lipid measures (LDL-C, TG and non-HDL-C) improved overall. These data are consistent with previously described lipid changes associated with puberty. (48) Nonetheless, even with traditional lipid measures, obesity was associated with the attenuation of these improvements. These observations suggest that the assessment of cardiovascular risk using NMR may be less prone to the confounding effects of puberty, and, therefore, more clearly reflective of CVD risk.

The major strength of this report is the ethnically diverse sample of US adolescents. It is also important to highlight that the current analyses were conducted on $87.4 \%$ of the overall participants with stored blood. Although this is a significant sub-group of the overall sample, the interpretation of our results requires caution, as there were some significant differences between the participants included versus those excluded from our analyses. Moreover, although self-reported physical activity and dietary data were collected from participants, the high levels of missing data on these variables prevented us from controlling for change in these variables.

It is also important to recognize that our period of assessment occurred when participants were progressing through puberty which exerts profound effects on key outcome variables. We employed a self-reported measure of puberty which, although shown to be valid in this group, is less accurate than physical examination; combined with the high levels of missing data at the $8^{\text {th }}$ grade meant that we cannot adjust for change in pubertal status. Although the models were adjusted for self-reported pubertal status it is possible that some residual confounding by pubertal stage might have remained. Finally, it is important to acknowledge that change in BMI category was used in the analyses and not change in absolute BMI. Among participants whose BMI improved, some participants would have improved more than others and this potential difference is not accounted for in the analysis.

\section{Acknowledgments}

Funded by the National Institute of Diabetes and Digestive and Kidney Diseases/National Institutes of Health (U01DK61230, U01-DK61249, U01-DK61231, and U01-DK61223) and the American Diabetes Association. All of the LipoScience testing was performed blinded, without any knowledge of the other clinical variables. The full analyses and associations reported upon in this report were performed independently by K.D. within the HEALTHY Data Coordinating Center. J.O. is employed by and is a stockholder of LipoScience, Inc, the diagnostic company that performed the NMR lipoprotein subclass analyses described in the manuscript. J.B. has consulted with LipoScience under contracts between his employer and the company; he has derived no direct financial benefit from this work.

We wish to thank the administration, faculty, staff, students, and their families at the middle schools and school districts that participated in the HEALTHY study. 


\section{References}

1. Laakso M, Sarlund H, Mykkanen L. Insulin resistance is associated with lipid and lipoprotein abnormalities in subjects with varying degrees of glucose tolerance. Arteriosclerosis. 1990; 10(2): 223-31. [PubMed: 2180396]

2. Kathiresan S, Otvos JD, Sullivan LM, Keyes MJ, Schaefer EJ, Wilson PW, et al. Increased small low-density lipoprotein particle number: a prominent feature of the metabolic syndrome in the Framingham Heart Study. Circulation. 2006; 113(1):20-9. [PubMed: 16380547]

3. Mora S, Otvos JD, Rosenson RS, Pradhan A, Buring JE, Ridker PM. Lipoprotein particle size and concentration by nuclear magnetic resonance and incident type 2 diabetes in women. Diabetes. 2010; 59(5):1153-60. [PubMed: 20185808]

4. Kuller L, Arnold A, Tracy R, Otvos J, Burke G, Psaty B, et al. Nuclear magnetic resonance spectroscopy of lipoproteins and risk of coronary heart disease in the cardiovascular health study. Arterioscler Thromb Vasc Biol. 2002; 22(7):1175-80. [PubMed: 12117734]

5. Magge SN, Prasad D, Koren D, Gallagher PR, Mohler ER 3rd, Stettler N, et al. Prediabetic obese adolescents have a more atherogenic lipoprotein profile compared with normoglycemic obese peers. J Pediatr. 2012; 161(5):881-6. [PubMed: 22622051]

6. Magge SN, Stettler N, Koren D, Levitt Katz LE, Gallagher PR, Mohler ER 3rd, et al. Adiponectin is associated with favorable lipoprotein profile, independent of BMI and insulin resistance, in adolescents. J Clin Endocrinol Metab. 2011; 96(5):1549-54. [PubMed: 21367935]

7. Mietus-Snyder M, Drews KL, Otvos JD, Willi SM, Foster GD, Jago R, et al. Low-Density Lipoprotein Cholesterol versus Particle Number in Middle School Children. J Pediatr. 2013

8. Shadid S, LaForge R, Otvos JD, Jensen MD. Treatment of obesity with diet/exercise versus pioglitazone has distinct effects on lipoprotein particle size. Atherosclerosis. 2006; 188(2):370-6. [PubMed: 16313908]

9. Juhola J, Magnussen CG, Viikari JS, Kahonen M, Hutri-Kahonen N, Jula A, et al. Tracking of serum lipid levels, blood pressure, and body mass index from childhood to adulthood: the Cardiovascular Risk in Young Finns Study. J Pediatr. 2011; 159(4):584-90. [PubMed: 21514597]

10. Marcus MD, Foster GD, El Ghormli L, Baranowski T, Goldberg L, Jago R, et al. Shifts in BMI category and associated cardiometabolic risk: prospective results from HEALTHY study. Pediatrics. 2012; 129(4):e983-91. [PubMed: 22430457]

11. Buse J, Hirst K. The HEALTHY study: introduction. Int J Obes (Lond). 2009; 33 (Suppl 4):S1-2. [PubMed: 19623183]

12. The Healthy Study Group. A School-Based Intervention for Diabetes Risk Reduction. N Engl J Med. 2010; 363(5):445-53.

13. DeBar LL, Schneider M, Ford EG, Hernandez AE, Showell B, Drews KL, et al. Social marketingbased communications to integrate and support the HEALTHY study intervention. Int J Obes (Lond). 2009; 33 (Suppl 4):S52-9. [PubMed: 19623190]

14. Gillis B, Mobley C, Stadler DD, Hartstein J, Virus A, Volpe SL, et al. Rationale, design and methods of the HEALTHY study nutrition intervention component. Int J Obes (Lond). 2009; 33 (Suppl 4):S29-36. [PubMed: 19623185]

15. Jago R, McMurray RG, Drews KL, Moe EL, Murray T, Pham TH, et al. HEALTHY Intervention: Fitness, Physical Activity, and Metabolic Syndrome Results. Med Sci Sports Exerc. 2011; 43(8): 1513-22. [PubMed: 21233778]

16. Venditti EM, Elliot DL, Faith MS, Firrell LS, Giles CM, Goldberg L, et al. Rationale, design and methods of the HEALTHY study behavior intervention component. Int J Obes (Lond). 2009; 33 (Suppl 4):S44-51. [PubMed: 19623189]

17. Foster GD, Linder B, Baranowski T, Cooper DM, Goldberg L, Harrell JS, et al. A school-based intervention for diabetes risk reduction. N Engl J Med. 2010; 363(5):443-53. [PubMed: 20581420]

18. Centers for Disease Control National Center for Health Statistics. 2000 CDC growth charts for the United States. Atlanta Centers for Disease Control; 2009. 
19. Flegal KM, Wei R, Ogden CL, Freedman DS, Johnson CL, Curtin LR. Characterizing extreme values of body mass index-for-age by using the 2000 Centers for Disease Control and Prevention growth charts. Am J Clin Nutr. 2009; 90(5):1314-20. [PubMed: 19776142]

20. Willi SM, Hirst K, Jago R, Buse J, Kaufman F, El Ghormli L, et al. Cardiovascular risk factors in multi-ethnic middle school students: the HEALTHY primary prevention trial. Pediatr Obes. 2012; 7(3):230-9. [PubMed: 22461375]

21. Fridewald WT, Levy RI, Fredrickson DS. Estimation of the concentration of low-density lipoprotein cholesterol in plasma, without use of the preparative ultracentrifuge. Clin Chem. 1972; 18:499-502. [PubMed: 4337382]

22. Matthews DR, Hosker JP, Rudenski AS, Naylor BA, Treacher DF, Turner RC. Homeostasis model assessment: insulin resistance and beta-cell function from fasting plasma glucose and insulin concentrations in man. Diabetologia. 1985; 28(7):412-9. [PubMed: 3899825]

23. Frazier-Wood AC, Garvey WT, Dall T, Honigberg R, Pourfarzib R. Opportunities for using lipoprotein subclass profile by nuclear magnetic resonance spectroscopy in assessing insulin resistance and diabetes prediction. Metab Syndr Relat Disord. 2012; 10(4):244-51. [PubMed: 22533466]

24. Petersen AC, Crockett L, Richards M, Boxer A. A self-report measure of pubertal status: reliability, validity, and initial norms. Youth Adol. 1988; 17:117-33.

25. Tanner, JM. Growth at adolescence. Oxford: Blackwell; 1962.

26. Decewicz DJ, Neatrour DM, Burke A, Haberkorn MJ, Patney HL, Vernalis MN, et al. Effects of cardiovascular lifestyle change on lipoprotein subclass profiles defined by nuclear magnetic resonance spectroscopy. Lipids Health Dis. 2009; 8:26. [PubMed: 19563671]

27. Naganuma R, Sakurai M, Miura K, Yoshita K, Morikawa Y, Kido T, et al. Relation of long-term body weight change to change in lipoprotein particle size in Japanese men and women: the INTERMAP Toyama Study. Atherosclerosis. 2009; 206(1):282-6. [PubMed: 19264306]

28. Goldberg R, Temprosa M, Otvos J, Brunzell J, Marcovina S, Mather K, et al. Lifestyle and Metformin Treatment Favorably Influence Lipoprotein Subfraction Distribution in the Diabetes Prevention Program. J Clin Endocrinol Metab. 2013; 98(10):3989-98. [PubMed: 23979954]

29. Magnussen CG, Thomson R, Cleland VJ, Ukoumunne OC, Dwyer T, Venn A. Factors affecting the stability of blood lipid and lipoprotein levels from youth to adulthood: evidence from the Childhood Determinants of Adult Health Study. Arch Pediatr Adolesc Med. 2011; 165(1):68-76. [PubMed: 21199983]

30. Harder H, Dinesen B, Astrup A. The effect os a rapid weight loss on lipid profile and glycemic control in obese type 2 diabetic patients. Int J Obes (Lond). 2004; 28:180-2.

31. Goff DC Jr, D’Agostino RB Jr, Haffner SM, Otvos JD. Insulin resistance and adiposity influence lipoprotein size and subclass concentrations. Results from the Insulin Resistance Atherosclerosis Study. Metabolism. 2005; 54(2):264-70. [PubMed: 15690322]

32. García-Sánchez C, Torres-Tamayo M, Juárez-Meavepeña M, López-Osorio C, Toledo-Ibelles P, Monter-Garrido M, et al. Lipid plasma concentrations of HDL subclasses determined by enzymatic staining on polyacrylamide electrophoresis gels in children with metabolic syndrome. Clin Chim Acta. 2011; 412:292-8. [PubMed: 21036160]

33. Krauss RM. Lipids and lipoproteins in patients with type 2 diabetes. Diabetes Care. 2004; 27(6): 1496-504. [PubMed: 15161808]

34. Rosenson RS, Brewer HB Jr, Chapman MJ, Fazio S, Hussain MM, Kontush A, et al. HDL measures, particle heterogeneity, proposed nomenclature, and relation to atherosclerotic cardiovascular events. Clin Chem. 2011; 57(3):392-410. [PubMed: 21266551]

35. Bibbins-Domingo K, Coxson P, Pletcher MJ, Lightwood J, Goldman L. Adolescent overweight and future adult coronary heart disease. N Engl J Med. 2007; 357(23):2371-9. [PubMed: 18057339]

36. Lightwood J, Bibbins-Domingo K, Coxson P, Wang YC, Williams L, Goldman L. Forecasting the future economic burden of current adolescent overweight: an estimate of the coronary heart disease policy model. Am J Public Health. 2009; 99(12):2230-7. [PubMed: 19833999] 
37. Wilson PW, D'Agostino RB, Parise H, Sullivan L, Meigs JB. Metabolic syndrome as a precursor of cardiovascular disease and type 2 diabetes mellitus. Circulation. 2005; 112(20):3066-72. [PubMed: 16275870]

38. Kavey RE, Mietus-Snyder M. Beyond cholesterol: the atherogenic consequences of combined dyslipidemia. J Pediatr. 2012; 161(6):977-9. [PubMed: 22910102]

39. Packard CJ, Demant T, Stewart JP, Bedford D, Caslake MJ, Schwertfeger G, et al. Apolipoprotein B metabolism and the distribution of VLDL and LDL subfractions. J Lipid Res. 2000; 41(2):30518. [PubMed: 10681415]

40. Ford MA, McConnell JP, Lavi S, Rihal CS, Prasad A, Sandhu GS, et al. Coronary artery endothelial dysfunction is positively correlated with low density lipoprotein and inversely correlated with high density lipoprotein subclass particles measured by nuclear magnetic resonance spectroscopy. Atherosclerosis. 2009; 207(1):111-5. [PubMed: 19515370]

41. Webber LS, Srinivasan SR, Wattingney WA, Berenson GS. Tracking of serum lipids and lipoproteins from childhood to adulthood: The Bogalusa Heart Study. Am J Epidemiol. 1991; 133:884-49. [PubMed: 2028978]

42. Huang TT, Nansel TR, Belsheim AR, Morrison JA. Sensitivity, specificity, and predictive values of pediatric metabolic syndrome components in relation to adult metabolic syndrome: the Princeton LRC follow-up study. J Pediatr. 2008; 152(2):185-90. [PubMed: 18206687]

43. Magnussen CG, Raitakari OT, Thomson R, Juonala M, Patel DA, Viikari JS, et al. Utility of currently recommended pediatric dyslipidemia classifications in predicting dyslipidemia in adulthood: evidence from the Childhood Determinants of Adult Health (CDAH) study, Cardiovascular Risk in Young Finns Study, and Bogalusa Heart Study. Circulation. 2008; 117(1): 32-42. [PubMed: 18071074]

44. Magnussen CG, Venn A, Thomson R, Juonala M, Srinivasan SR, Viikari JS, et al. The association of pediatric low- and high-density lipoprotein cholesterol dyslipidemia classifications and change in dyslipidemia status with carotid intima-media thickness in adulthood evidence from the cardiovascular risk in Young Finns study, the Bogalusa Heart study, and the CDAH (Childhood Determinants of Adult Health) study. J Am Coll Cardiol. 2009; 53(10):860-9. [PubMed: 19264243]

45. Daniels SR. Can lipid and lipoprotein concentrations in childhood predict adult atherosclerosis? J Am Coll Cardiol. 2009; 10(53):870-1. [PubMed: 19264244]

46. Li S, Chen W, Srinivasan SR, Xu J, Berenson GS. Relation of childhood obesity/cardiometabolic phenotypes to adult cardiometabolic profile: the Bogalusa Heart Study. Am J Epidemiol. 2012; 176 (Suppl 7):S142-9. [PubMed: 23035138]

47. Garvey WT, Kwon S, Zheng D, Shaughnessy S, Wallace P, Hutto A, et al. Effects of insulin resistance and type 2 diabetes on lipoprotein subclass particle size and concentration determined by nuclear magnetic resonance. Diabetes. 2003; 52(2):453-62. [PubMed: 12540621]

48. Daniels SR, Greer FR. Committee on N. Lipid screening and cardiovascular health in childhood. Pediatrics. 2008; 122(1):198-208. [PubMed: 18596007]

\section{Appendix}

Members of the HEALTHY Study Group include (* indicates principal investigator or director): Study Chair--Children's Hospital Los Angeles: F.R. Kaufman.

Field Centers--Baylor College of Medicine: T. Baranowski*, L. Adams, J. Baranowski, A. Canada, K.T. Carter, K.W. Cullen, M.H. Dobbins, R. Jago, A. Oceguera, A.X. Rodriguez, C. Speich, L.T. Tatum, D. Thompson, M.A. White, C.G. Williams; Oregon Health \& Science University: L. Goldberg*, D. Cusimano, L. DeBar, D. Elliot, H.M. Grund, S. McCormick, E. Moe, J.B. Roullet, D. Stadler; Temple University: G. Foster* (Steering Committee Chair), J. Brown, B. Creighton, M. Faith, E.G. Ford, H. Glick, S. Kumanyika, J. Nachmani, L. Rosen, S. Sherman, S. Solomon, A. Virus, S. Volpe, S. Willi; University of 
California at Irvine: D. Cooper*, S. Bassin, S. Bruecker, D. Ford, P. Galassetti, S.

Greenfield, J. Hartstein, M. Krause, N. Opgrand, Y. Rodriguez, M. Schneider; University of North Carolina at Chapel Hill: J. Harrell*, A. Anderson, T. Blackshear, J. Buse, J. Caveness, A. Gerstel, C. Giles, W. Hall, A. Jessup, P. Kennel, R. McMurray, A-M. Siega-Riz, M. Smith, A. Steckler, A. Zeveloff; University of Pittsburgh: M.D. Marcus*, M. Carter, S. Clayton, B. Gillis, K. Hindes, J. Jakicic, R. Meehan, R. Noll, J. Vanucci, E. Venditti; University of Texas Health Science Center at San Antonio: R. Treviño*, A. Garcia, D. Hale, A. Hernandez, I. Hernandez, C. Mobley, T. Murray, J. Stavinoha, K. Surapiboonchai, Z. Yin.

Coordinating Center--George Washington University: K. Hirst*, K. Drews, S. Edelstein, L. El ghormli, S. Firrell, M. Huang, P. Kolinjivadi, S. Mazzuto, T. Pham, A. Wheeler.

Project Office--National Institute of Diabetes and Digestive and Kidney Diseases: B. Linder*, C. Hunter, M. Staten.

Central Biochemistry Laboratory--University of Washington Northwest Lipid Metabolism and Diabetes Research Laboratories: S.M. Marcovina.* 

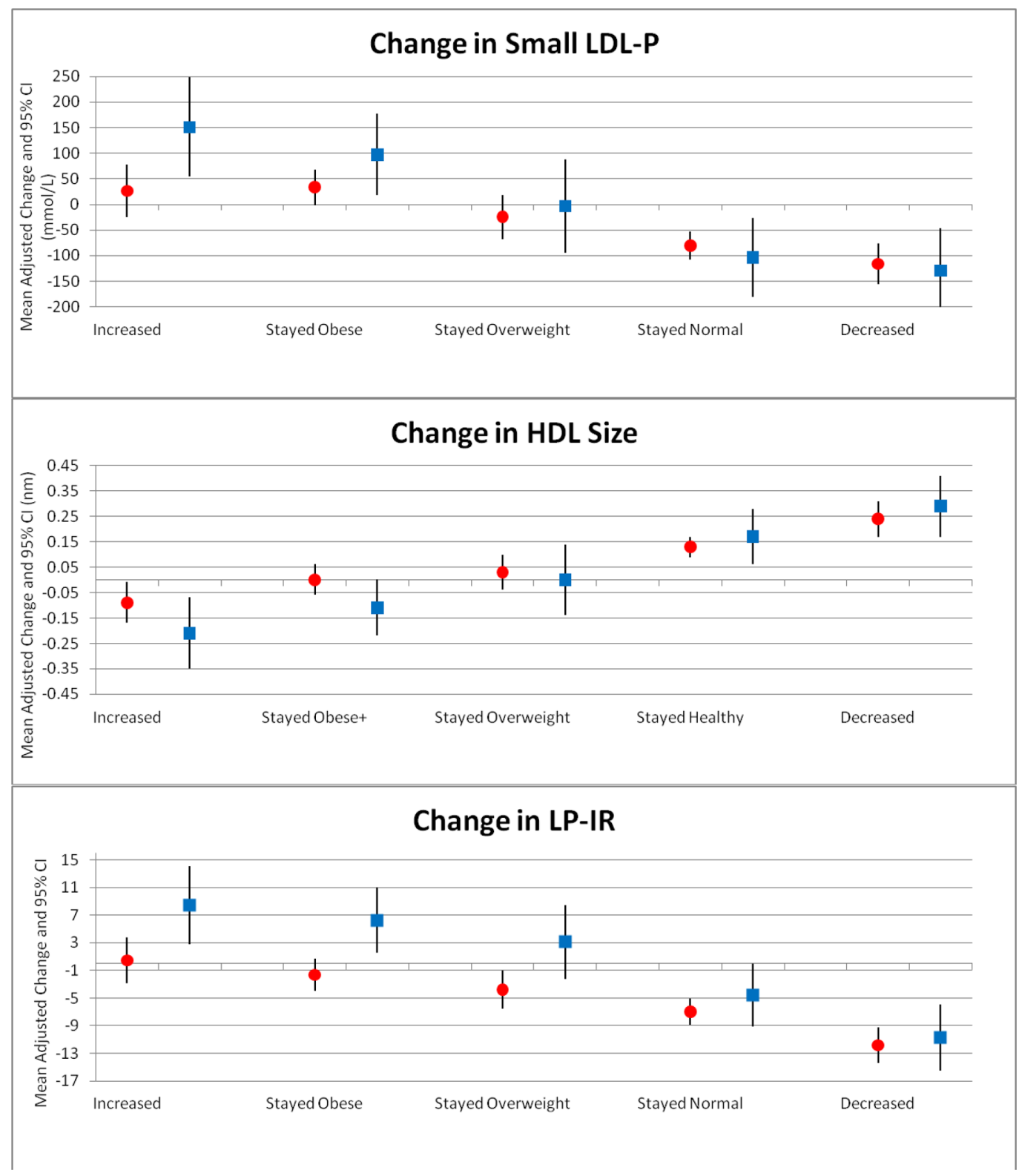

* Girls are denoted by circles in figures and boys by squares.

Figure 1.

Changes (95\% CI) in small LDL-P, HDL size, and LP-IR in boys and girls as a function of BMI Category Shifts from 6th Grade to 8th Grade *

* Girls are denoted by circles in figures and boys by squares. 


\section{Table 1}

Baseline Participant Characteristics $(\mathrm{N}=2069)$ and p-values testing for sex differences

\begin{tabular}{|c|c|c|c|c|}
\hline & OVERALL & Female (N=1115) & Male (N=954) & \\
\hline & Mean (SD) or N and \% & Mean (SD) or N and \% & Mean (SD) or N and \% & p-value \\
\hline Age (years) & $11.29(0.57)$ & $11.24(0.54)$ & $11.35(0.60)$ & $<.0001$ \\
\hline BMI Percentile & $73.65(27.59)$ & $72.21(27.42)$ & $75.32(27.72)$ & 0.0105 \\
\hline BMI Category & & & & 0.0005 \\
\hline$<85^{\text {th }}$ Percentile & $101849.2 \%$ & $58852.7 \%$ & $43045.1 \%$ & \\
\hline $85^{\text {th }}-94^{\text {th }}$ Percentile & $40219.4 \%$ & $22219.9 \%$ & $18018.9 \%$ & \\
\hline$\geq 95^{\text {th }}$ Percentile & $64931.4 \%$ & $30527.4 \%$ & $34436.1 \%$ & \\
\hline Race/Ethnicity & & & & 0.0499 \\
\hline Hispanic & $126861.3 \%$ & $68861.7 \%$ & $58060.8 \%$ & \\
\hline Black & $38618.7 \%$ & $21819.6 \%$ & $16817.6 \%$ & \\
\hline White & $41520.1 \%$ & $20918.7 \%$ & $20621.6 \%$ & \\
\hline $\begin{array}{l}\text { Positive Reported } 1^{\text {st }} \text { Degree Family History of } \\
\text { Diabetes }\end{array}$ & $26512.8 \%$ & $14112.6 \%$ & $12413.0 \%$ & 0.8168 \\
\hline Highest Household Education & & & & 0.0989 \\
\hline No HS Diploma & $55626.9 \%$ & $31528.3 \%$ & $24125.3 \%$ & \\
\hline Some college & $110053.2 \%$ & $59353.2 \%$ & $50753.1 \%$ & \\
\hline College grad or higher & $41320.0 \%$ & $20718.6 \%$ & $20621.6 \%$ & \\
\hline Pubertal Status & & & & $<.0001$ \\
\hline Tanner Stage 1 & $2029.8 \%$ & $595.3 \%$ & $14315.0 \%$ & \\
\hline Tanner Stage 2 & $53525.9 \%$ & $14813.3 \%$ & $38740.6 \%$ & \\
\hline Tanner Stage 3 & $84941.0 \%$ & $47943.0 \%$ & $37038.8 \%$ & \\
\hline Tanner Stage 4 & $43621.1 \%$ & $38434.4 \%$ & $525.5 \%$ & \\
\hline Tanner Stage 5 & $472.3 \%$ & $454.0 \%$ & $20.2 \%$ & \\
\hline
\end{tabular}




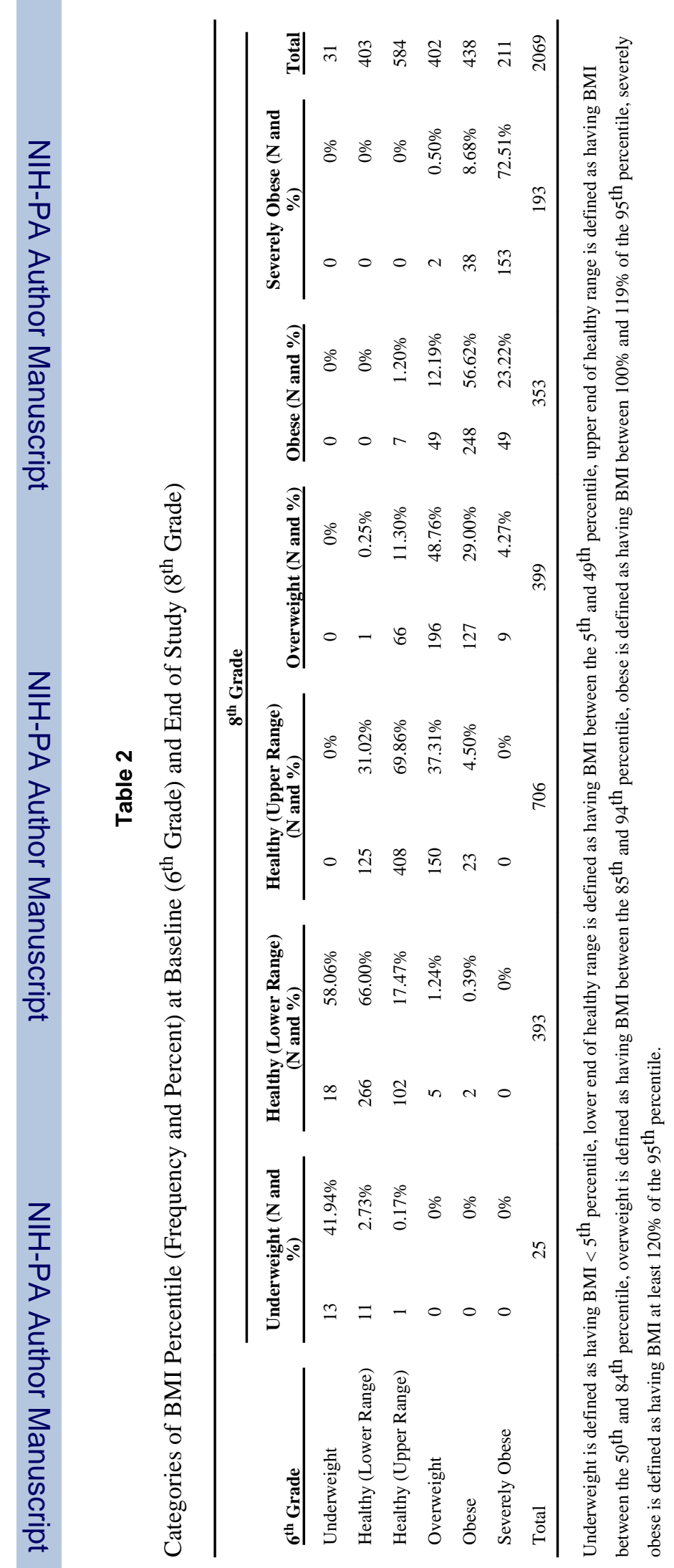

J Pediatr. Author manuscript; available in PMC 2015 May 01. 
Table 3

6th Grade, 8th Grade and Change (8th-6th) in BMI, Waist Circumference, HOMA-IR and NMR Variables with Underweight Dropped

\begin{tabular}{lccc}
\hline & $\mathbf{6}^{\text {th }}$ Grade & $\mathbf{8}^{\text {th }}$ Grade & Difference (8th-6th) \\
\cline { 2 - 4 } BMI Percentile & $75.06(73.92,76.19)$ & $74.45(73.38,75.52)$ & $-0.60(-1.17,-0.04)$ \\
Waist Circumference (cm) & $76.36(75.73,76.99)$ & $81.01(80.38,81.64)$ & $4.60(4.31,4.89)$ \\
Glucose & $93.70(93.42,93.99)$ & $94.23(93.86,94.61)$ & $0.53(0.16,0.90)$ \\
Insulin & $13.62(13.12,14.11)$ & $17.45(16.78,18.12)$ & $3.83(3.23,4.43)$ \\
HOMA-IR & $3.19(3.07,3.31)$ & $4.12(3.95,4.28)$ & $0.93(0.78,1.08)$ \\
Total Cholesterol & $155(139,174)$ & $146(130,164)$ & $-9(-22,4)$ \\
LDL-C (mg/dL) & $86(71,101)$ & $78(65,93)$ & $-7(-17,3)$ \\
LDL-P (nmol/L) & $682(516,894)$ & $636(495,832)$ & $-39(-179,90)$ \\
IDL-P (nmol/L) & $113(72,164)$ & $88(55,126)$ & $-23(-74,21)$ \\
Large LDL-P (nmol/L) & $312(186,434)$ & $319(200,435)$ & $13(-106,133)$ \\
Small LDL-P (nmol/L) & $189(27,495)$ & $147(27,438)$ & $-6(-174,67)$ \\
LDL Particle Size (nm) & $21.5(20.7,22.2)$ & $21.6(20.9,22.2)$ & $0.1(-0.6,0.7)$ \\
Non-HDL-C (mg/dL) & $103(87,121)$ & $94(79,110)$ & $-8(-20,2)$ \\
HDL-C (mg/dL) & $51(44,59)$ & $50(43,59)$ & $0(-6,5)$ \\
HDL-P (umol/L) & $33.0(30.4,35.8)$ & $31.7(29.1,34.2)$ & $-1.5(-4.1,1.5)$ \\
Large HDL-P (umol/L) & $6.0(3.9,8.5)$ & $6.2(4.1,8.8)$ & $0.2(-1.1,1.5)$ \\
Medium HDL-P (umol/L) & $10.2(7.6,13.1)$ & $9.1(6.6,11.9)$ & $-1.0(-3.9,1.6)$ \\
Small HDL-P (umol/L) & $16.3(13.7,19.1)$ & $15.9(13.2,18.5)$ & $-0.6(-3.2,1.9)$ \\
HDL Particle Size (nm) & $9.5(9.2,9.9)$ & $9.6(9.2,9.9)$ & $0.0(-0.2,0.3)$ \\
Triglycerides (mg/dL) & $78(56,108)$ & $72(53,99)$ & $-6(-26,13)$ \\
Triglycerides:HDL-C & $1.5(1.0,2.3)$ & $1.4(1.0,2.1)$ & $-0.1(-0.6,0.3)$ \\
VLDL-P (umol/L) & $38.1(25.4,54.9)$ & $34.3(23.8,50.8)$ & $-3.0(-15.3,9.3)$ \\
Large VLDL-P (umol/L) & $2.0(1.2,4.0)$ & $1.7(1.1,2.8)$ & $-0.3(-1.6,0.5)$ \\
Medium VLDL-P (umol/L) & $14.4(8.1,24.2)$ & $13.2(7.2,22.7)$ & $-1.1(-8.0,5.8)$ \\
Small VLDL-P (umol/L) & $19.3(12.1,27.7)$ & $18.0(12.0,26.2)$ & $-1.0(-9.3,7.2)$ \\
VLDL Particle Size (nm) & $49.7(46.7,53.3)$ & $49.1(46.3,52.6)$ & $-0.6(-4.4,3.0)$ \\
LP-IR & $35(21,53)$ & $31(18,48)$ & $-3(-14,7)$ \\
\hline & & & \\
\hline
\end{tabular}

HOMA-IR, Total Cholesterol, LDL-C, LDL-P, IDL-P, Large LDL-P, Small LDL-P, LDL Particle Size, HDL-C, HDL-P, Large HDL-P, Medium HDL-P, Small HDL-P, HDL Particle Size, Triglycerides, Triglyceride:HDL-C, VLDL-P, Large VLDL-P, Medium VLDL-P Small VLDL-P, VLDL Particle Size, and LP-IR are presented as medians and $\left(25^{\text {th }}\right.$ percentile, $75^{\text {th }}$ percentile) while BMI percentile, waist circumference, glucose, and insulinare presented as mean and $95 \%$ confidence interval. 


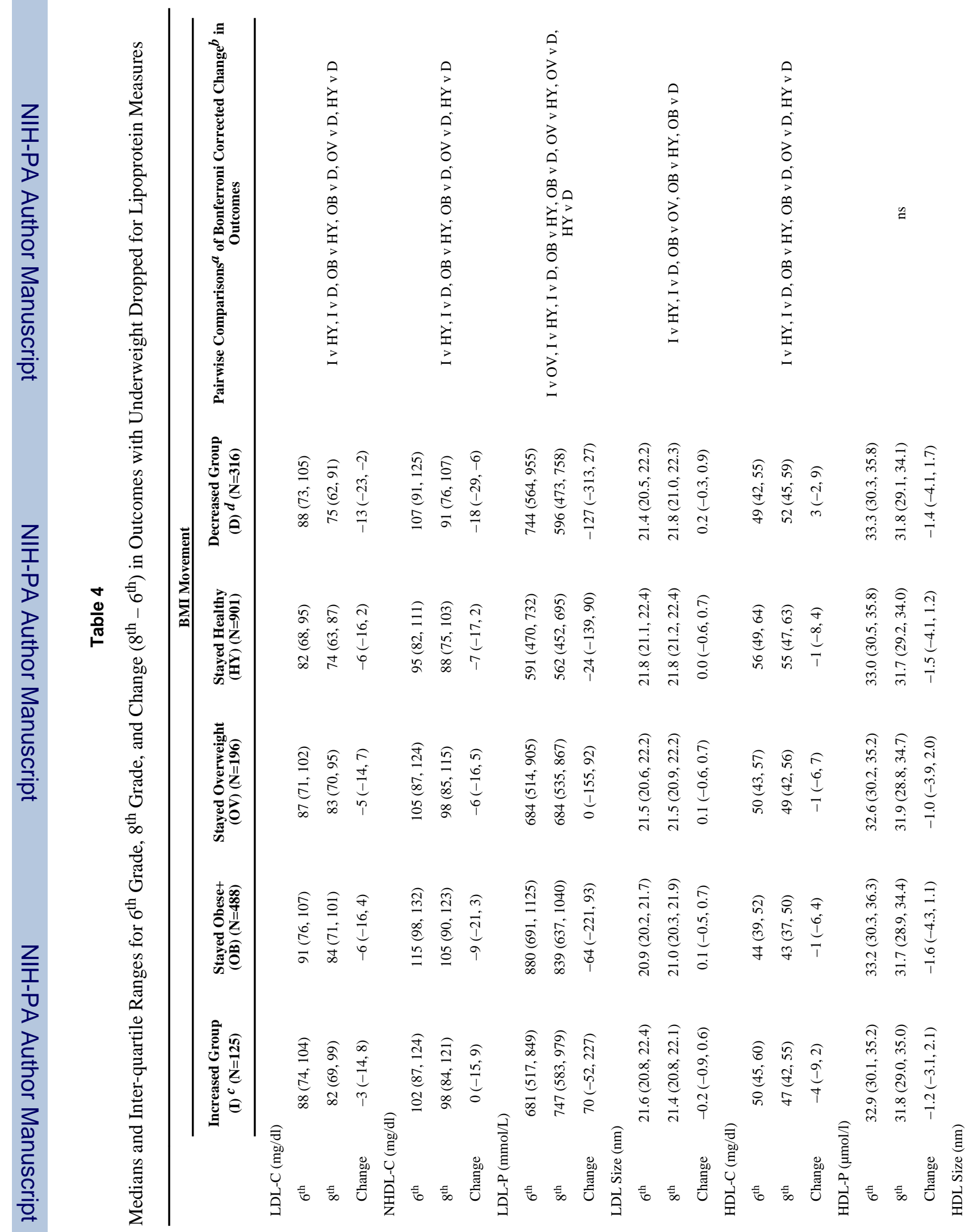




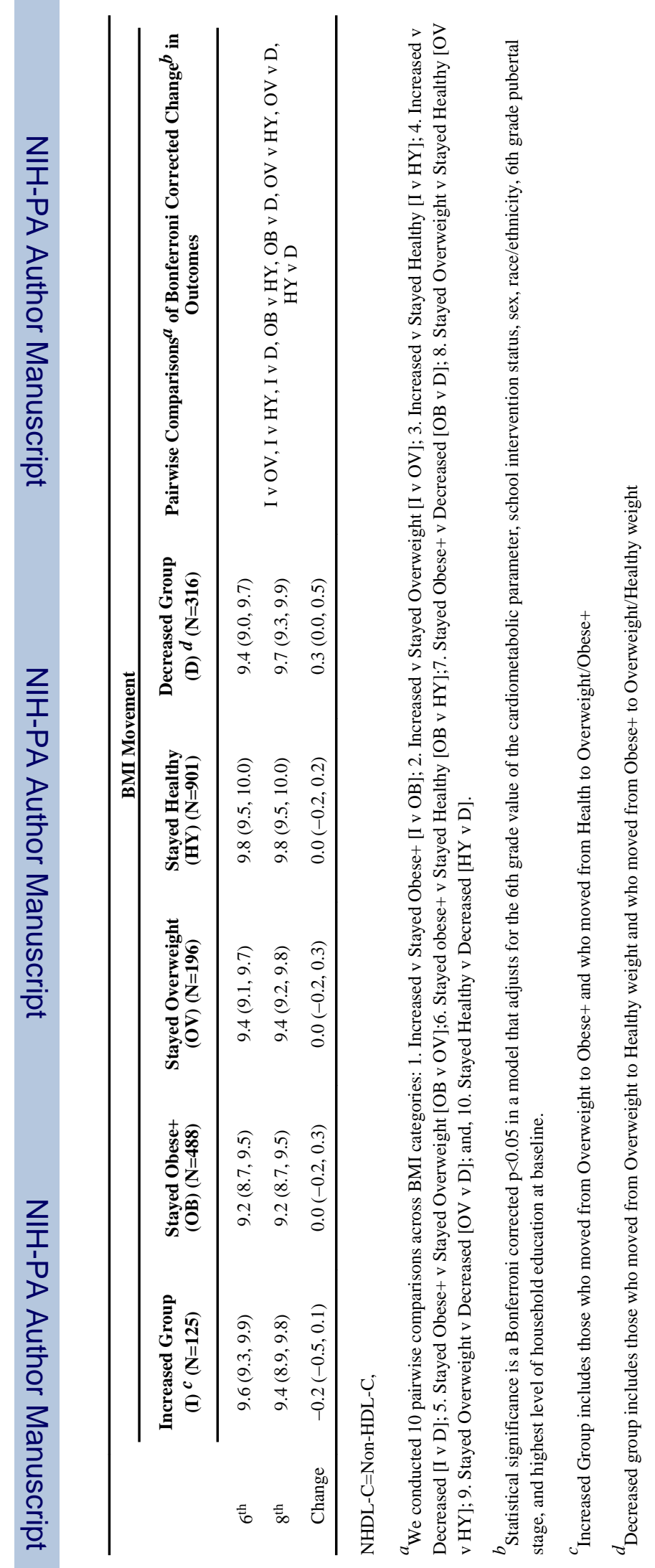

J Pediatr. Author manuscript; available in PMC 2015 May 01. 


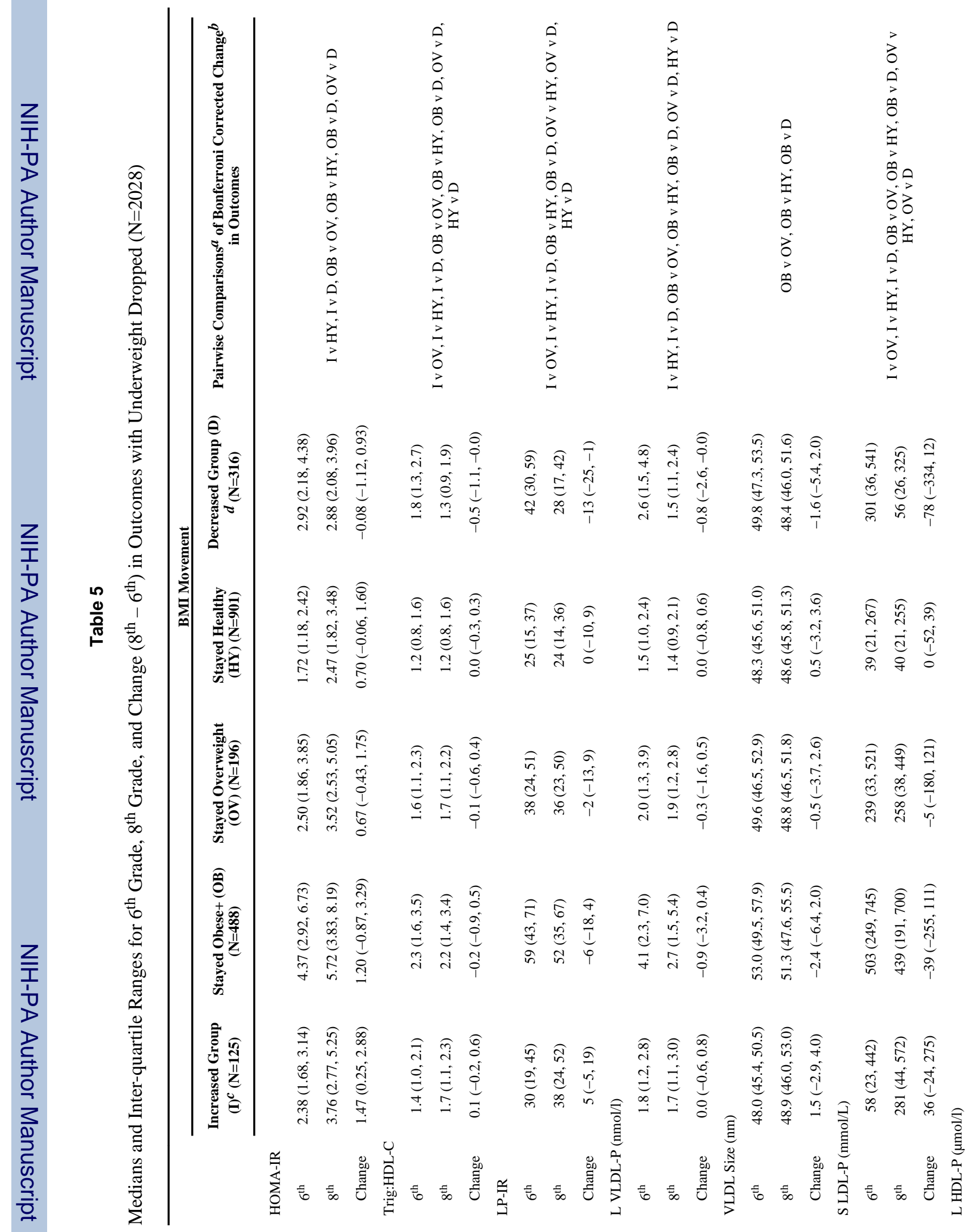




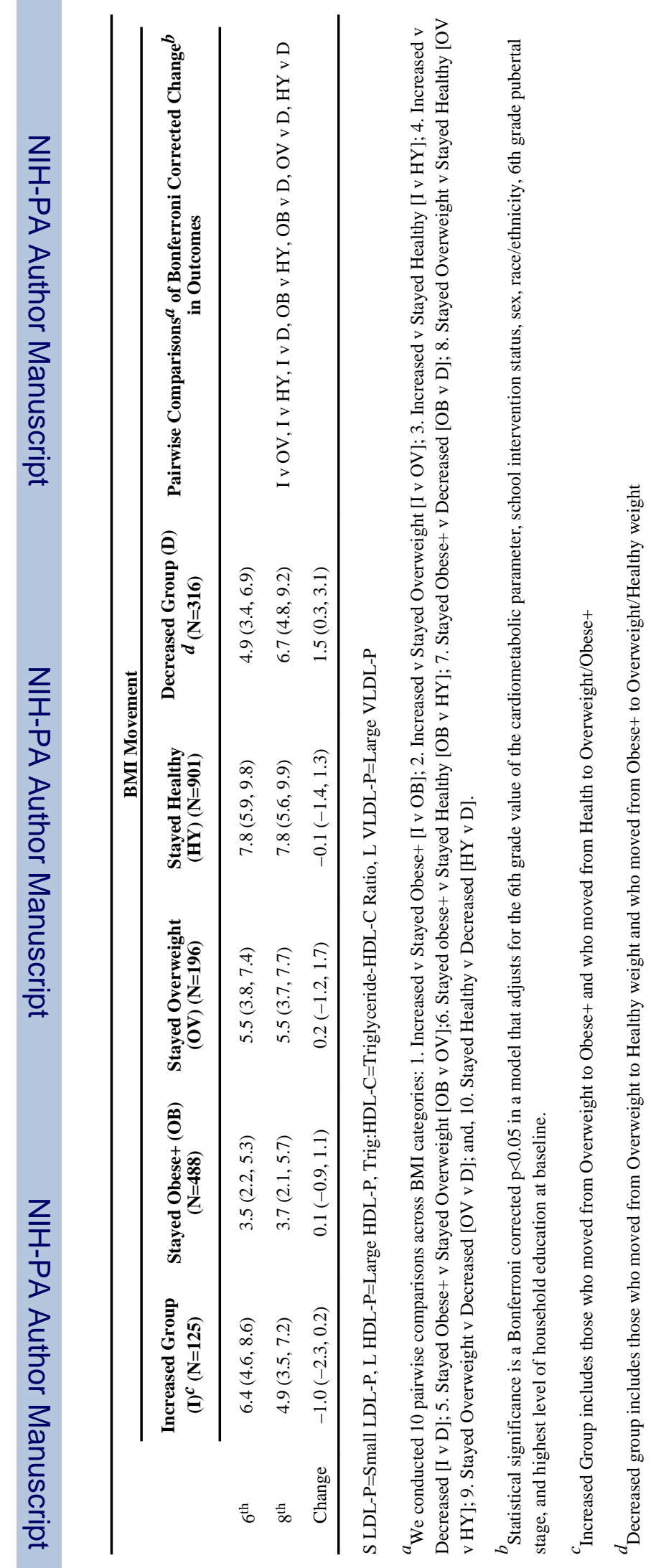

J Pediatr. Author manuscript; available in PMC 2015 May 01. 